\title{
NO-DUALIDAD EN LAS SABIDURÍAS ORIENTALES
}

\section{NONDUALITY IN ORIENTAL WISDOM SYSTEMS}

\author{
Hang FERRER MORA* \\ UNIVERSITAT DE VALÈNCIA
}

Resumen: El presente artículo se centra en el concepto de no-dualidad en las sabidurías orientales. En primer lugar, se expondrán y comentarán sus definiciones y su relevancia en el pensamiento y la filosofía oriental. Tras analizar los diferentes significados de no-dualidad propuestos por Loy, se trazará su origen en el taoísmo, budismo, zen, hinduismo y vedanta advaita. Además, se examinarán los principales textos de las sabidurías orientales mencionadas anteriormente para encontrar posibles afirmaciones no-duales.

Palabras Clave: No-dualidad, sabidurías orientales, taoísmo, budismo, zen, hinduismo, vedanta advaita.

Aвstract: This paper focuses on the concept of nonduality in Oriental wisdom systems. Firstly, its definitions and relevance in Oriental thought and Eastern philosophy will be discussed. After analyzing the different meanings of nonduality proposed by Loy, we will trace its origin back to Taoism, Buddhism, Zen, Hinduism and Advaita Vedanta. Furthermore, some of the main texts of the aforementioned Oriental wisdom systems will be examined in order to find possible nondual statements.

KeYwords: Nonduality, Oriental wisdom systems, Taoism, Buddhism, Zen, Hinduism, Advaita Vedanta.

\footnotetext{
* Profesor Titular de la Facultad de Filología, Traducción y Comunicación de la Universitat deValència. Email: hang.ferrer@uv.es. El autor del presente artículo es asimismo alumno en el Programa de Doctorado en Filosofía de la Universidad Nacional de Educación a Distancia (UNED).
} 
La no-dualidad es uno de los conceptos procedentes del Lejano Oriente que ha penetrado en Occidente gracias a la permeabilidad cultural y al creciente interés por ideas, conceptos y creencias que englobamos aquí bajo el epígrafe de sabidurias orientales ${ }^{1}$.

El presente artículo tiene como objeto hacer un recorrido por el concepto de no-dualidad en las principales sabidurías orientales en varios pasos:

1) Determinar y definir el objeto de estudio, la no-dualidad. Como punto de partida, se expondrán las definiciones de Loy $^{2}$ para abordar el concepto en su contexto. A pesar de la proliferación del término de estudios y corrientes de pensamiento orientalistas en Occidente, el término no-dualidad no tiene allí una larga tradición; veremos qué cuestiones filosóficas plantean estas acepciones.

2) Rastrear pensamientos y afirmaciones no-duales, tanto explícitas como implícitas, en las principales sabidurías orientales, a saber: taoísmo, hinduismo (con énfasis en el vedanta advaita como doctrina no-dual por excelencia) y budismo (con especial incidencia en el budismo zen). Se expondrán algunas citas procedentes de sus textos que ilustren la no-dualidad.

\section{La no-dualidad como concepto}

El concepto no-dualidad ha hecho un largo recorrido desde el Lejano Oriente. Aunque se pueda colegir que su significado se deriva simplemente de una negación de la dualidad, este es mucho más amplio y abarca otros aspectos que enumeramos a continuación, tal y como lo recoge Loy (2000: 17):

1. negación del pensamiento dualista;

2. no-pluralidad del mundo;

3. ausencia de toda diferenciación entre sujeto y objeto;

1 El concepto sabiduría oriental (Román López, 2004) designa sistemas filosóficos, religiosos, etc. surgidos en Asia Oriental. Desde su propia concepción no se trata meramente de filosofías o religiones, tal y como se entienden en Occidente.

2 Loy (1999). Nonduality. Las citas proceden de su traducción en español, No-dualidad (ver bibliografía). 
4. identidad entre los fenómenos y el Absoluto o la equiparación que efectúa el budismo mahāyāna ${ }^{3}$ entre samisāra y nirvāṇa ${ }^{4}$;

5. la posibilidad de la unión mística entre Dios y el ser humano.

Nos centraremos en las tres primeras acepciones en el presente artículo, que son las definiciones propias de no-dualidad en sí, para determinar su origen en las sabidurías orientales. La cuarta acepción, de naturaleza más concreta, y la quinta, que entronca con las corrientes místicas de las religiones monoteístas occidentales, no serán objeto de estudio pormenorizado en este contexto.

\subsection{La negación del pensamiento dualista}

En primer lugar, la no-dualidad cuestiona en 1) el pensamiento dualista, entendido como modo de categorizar y percibir el universo, presente ya en algunas filosofías orientales de la antigüedad, p. ej. el concepto de yin y yang en el taoísmo ${ }^{5}$. Recordemos que el pensamiento dualista divide la realidad en dos categorías opuestas y antagónicas, denominados contrarios $^{6}$. Desde el dualismo con matiz religioso, también presente en el pensamiento occidental desde la Antigüedad, existe la oposición entre el bien, identificado con la luz y el espíritu, y el mal, propio de las tinieblas y la materia; pero al elegir uno de los contrarios, también se elige de algún modo el otro, porque ambos son interdependientes. Como muestra Nāgārjuna en el Mūlamadhyamikakārikā̄, el bien existe sólo en una escala y en relación al mal. De este modo, la no-dualidad pone en entredicho

\footnotetext{
3 Acerca del budismo mahāyāna, véase el apartado 4.1. del presente artículo.

4 Los diacríticos empleados son fruto de la transliteración del sánscrito al alfabeto latino; sin embargo, prescindiremos de estos signos en este artículo, sobre todo con términos con más tradición como p. ej. nirvana; sin embargo, se respetarán si son citas literales de otros autores. Más sobre el significado de samsara y nirvana, véase el apartado 3.2.

5 Véase el apartado 2.1.

6 Como categorías gramaticales semánticas, los antónimos son palabras de la misma categoría gramatical que expresan ideas o conceptos opuestos o contrarios. Los hay graduales (p. ej. pobre-rico), que admiten diferentes niveles en medio, y contrarios o complementarios, porque uno excluye el otro (p. ej. vivo-muerto).

$7 \mathrm{El}$ «mal» sólo existe en relación al «bien» y es con respecto a lo «malo» como nos forjamos una idea de lo «bueno». Por tanto, la noción de «bien» resulta inseparable de la noción de «mal» y, del mismo modo, la noción de «mal» depende también de la noción de «bien» (Nāgārjuna, 1986: 10-11).
} 
e intenta superar la conceptualización del universo como una expresión de opuestos duales.

Sin embargo, surgen algunas preguntas problemáticas sobre la esencia del proceso cognitivo humano al considerar como uno un concepto y su contrario, ya que el lenguaje categoriza, aprehende, pero también clasifica y divide el mundo en objetos diferenciados y discretos, pero no deja de ser un mapa de la realidad: representa a sus denotados, pero no es la realidad en sí, a pesar de que, en ciertas cosmogonías, la palabra precede a la existencia del mundo e incluyo lo crea. Podemos afirmar que el valle necesita la montańa para definir su ser, y cuando observamos la realidad, ambos constituyen un continuum sin un límite claramente trazado, pero el lenguaje, al denominarlos y representarlos mediante palabras o conceptos mentales, los convierte en categorías discretas y separadas, es decir, duales. Al mismo tiempo, el lenguaje constituye el instrumento principal del pensamiento lógico, con una limitación muy clara, como apunta Martín: «Es evidente que el pensamiento lógico es mero instrumento, cual mecánico ordenador, incapaz de contemplar directamente la verdad. Y de sus rodeos impotentes surge la opinión, muy común, de que las verdades son relativas. En efecto, con el instrumento lógico pensante se puede demostrar una idea y la contraria con todo rigor lógico y científico. ¿Quiere esto decir que la verdad absoluta no existe?» (Martín, 2005: 14).

Esta cuestión lleva a paradojas de formulación para pensar y postular la nodualidad: «¿Qué tipo de pensamiento queda? Si el lenguaje es esencialmente dicotomizador (en el sentido de que escinde al sujeto del predicado/atributo) ¿Cómo podemos hablar de un pensamiento no-dual o no-conceptual? ¿Es posible vivir acaso prescindiendo de toda categoría dualista?» (Loy, 2000: 35). Esta escisión entre sujeto y objeto representa otro punto que habrá que revisar, puesto que la relación entre ambos es dual, como apunta la definición en 2) y su negación en 3). En Oriente dan cuenta de este problema y proponen alternativas al conocimiento verbal racional a través del lenguaje. Veremos a lo largo de este trabajo algunas de las respuestas que dan las sabidurías orientales. 


\subsection{La no-pluralidad del mundo}

La no-pluralidad del mundo en 2) postula que el universo es no-plural en el sentido de que todo lo que se halla en él no son cosas diferentes y diferenciadas, sino que forman parte de una misma totalidad integral. La idea de unidad, de que todo es uno, de una totalidad indivisible carente de principio y de fin, es lo que diferentes tradiciones orientales entienden por tao o Brahman ${ }^{8}$. En un sentido amplio, la no-dualidad se podría interpretar como una forma de monismo. Sin embargo, en sentido estricto, la no-dualidad no debe entenderse como una interpretación del monismo desde el pensamiento filosófico occidental, ya que la no-dualidad no afirma que todo en el universo se compone de la misma sustancia indiferenciada desde el plano material. Más bien, se ha de situar en una concepción desde un plano más amplio que trasciende la materia.

En muchas de las sabidurías orientales, pero también en la tradición filosófica occidental ${ }^{9}$, se encuentra esta descripción de naturaleza espiritual de la totalidad del mundo y el universo, la existencia de una conciencia o de una "Mente única» ${ }^{10}$. Sólo cuando el ser humano a través del lenguaje y de sus juicios comienza a hacer distinciones, surge la conciencia de la diferenciación, y, por tanto, la conciencia de la existencia de sujeto y objeto, la conciencia de la dualidad: «Todo [el universo] permanecía en un estado indiferenciado hasta que comenzó a diferenciarse a causa de los nombres y las formas. Entonces fue conocido con ese o aquel nombre y con esta o aquella forma [Y así se dice]: Posee tal nombre y tal forma.» ${ }^{11}$

Este mecanismo de diferenciación que se usa mediante el nombre se basa en el lenguaje y se denomina nämarūpa (nombre y forma), lo cual nos remite a la problemática relación aún no resuelta entre el lenguaje y el mundo. Más allá,

8 Para profundizar sobre la relación del tao y Brahman y la no-dualidad, véase el apartado 2.1. y 3.3., respectivamente.

9 «En su [referido a Platón] vital demanda necesita hacer metafísica, comprender la realidad como un todo único. [...] cuando no se traspasa el nivel lógico como parece haberles sucedido a tantos filósofos conocidos y desconocidos, ese intento puede acabar en la construcción de fragmentadas doctrinas explicativas, fruto de una demanda insuficiente de verdad. Kant denunció los límites del conocer racional sin sospechar una evidencia detrás, aunque aludiera a una objetiva realidad nouménica.» (Martín, 2005: 14-15).

10 Cf. Loy, op. cit., p. 36.

11 Brihadāranyaka Upanișad, I, IV 7. Las adiciones entre corchetes son de Nikhilananda. (Fragmento citado en Loy, op. cit., p. 37). 
el motivo de que el ser humano experimente el mundo como una pluralidad se basa en que el pensamiento conceptual es dualista a causa de la naturaleza misma del lenguaje.

Entonces, ¿̨la percepción del mundo y sus múltiples objetos particulares son fenómenos ilusorios («māyā» según el vedanta)? Si la no-pluralidad residiera en la unidad fenoménica sería aceptar una base monista ${ }^{12}$ subyacente, lo que resulta problemático porque nos remite a otro tipo de dualidad entre la mente y los fenómenos o entre la dualidad y la no-dualidad ${ }^{13}$. Sin embargo, para el taoísmo y el hinduismo, respectivamente, el tao y el $\bar{a} t m a n^{14}$ son la causa primera creadora del mundo fenoménico, que está impregnado de su esencia espiritual.

\subsection{La ausencia de toda diferenciación entre sujeto y objeto}

La acepción de no-dualidad en 3) constituye uno de los principios fundamentales en muchos de los sistemas filosóficos orientales, y consiste en la no diferenciación entre el sujeto, el experimentador, y el objeto, que puede tratarse de un objeto sensorial, de una acción física o de un evento mental ${ }^{15}$.

En las Upanishads ${ }^{16}$ se hallan diversos pasajes que aluden a este tipo de nodualidad aplicado a los sentidos, cuando afirma, por ejemplo, que no hay visión separada del vidente (entendido como el sujeto que ve), y más allá de los sentidos, se aplica también al pensamiento, al habla y al conocimiento. La ciencia, incluso la más joven física cuántica, da cuenta de la «paradoja del observador», puesto que el sujeto que observa y el objeto observado son interdependientes, y al observar el objeto, el sujeto lo altera, por lo que el sujeto no puede ser eliminado sin transformar la naturaleza del objeto, y viceversa, como postulaba el vedanta advaita (cf. Loy, 1999: 28). Nuestra experiencia nunca ha dejado de ser no-dual. Los caminos espirituales propuestos por estas filosofías, aparentemente

\footnotetext{
12 El monismo, explicado de modo simplista y reduccionista, postula la existencia de una misma naturaleza de objeto, mientras la no-dualidad postula la no diferenciación o separación entre el sujeto y el objeto, como se expone en el presente capítulo.

13 Cf. Loy, op. cit., p. 39.

14 Véase el apartado 3.2.

15 Cf. Loy, op. cit., p. 40.

16 Acerca de las Upanishads, véase el apartado 3.1.
} 
diferentes, conducen a superar la ilusión de dualidad, para llegar a comprender y, sobre todo, experimentar la realidad no-dual última.

También en el budismo se presenta esta concepción de no-dualidad, pero presenta variaciones según las diferentes tradiciones. El Canon pali ${ }^{17}$, basado en las enseñanzas originales del Buda, sostiene un punto de vista más pluralista, ya que postula que la realidad se halla formada por múltiples objetos discretos. El budismo pali no afirma la no-dualidad plenamente, a pesar de sus comentarios en contra del pensamiento dualista, mientras que en los textos del budismo mahaya$n \mathrm{n}^{18}$ a menudo sí que se menciona explícitamente lo ilusorio de la diferenciación entre el sujeto y el objeto; no obstante, el mädhyamaka -el sistema filosófico más importante del mahayana- tampoco afirma contundentemente la no-dualidad, ya que rechaza todo posicionamiento filosófico: «el mādhyamaka es advayavāda (no-dos [...] que supone [...] la refutación de dos visiones alternativas, es decir, la primera aceptación de la no-dualidad) pero no es advaitavāda (no-diferenciación entre sujeto y objeto...)» (Loy, 2000: 43). Cabe recordar aquí que la primera acepción de no-dualidad se deriva de la negación de concebir el mundo como un sistema de opuestos, no afirma que el sujeto y objeto sean la misma sustancia indiferenciada, sino más bien destaca su interdependencia, y que la existencia de uno, por lo tanto, va pareja a la existencia del otro, y esta relación es indisoluble.

En los escritos del yogācāra ${ }^{19}$ se encuentran numerosos pasajes en los que se afirma explícitamente la identidad entre el sujeto y el objeto. El yogācāra postula que en el estado de realización absoluta (parinispannasvabhäba), «el estado más elevado de la existencia, la experiencia trasciende toda dualidad entre sujeto y objeto $»^{20}$, lo que equivale a decir que la experiencia es no-dual.

La no-dualidad entre sujeto y objeto también constituye el eje principal de los tantras hindú y budista ${ }^{21}$ y es el principio de la unión de toda dualidad en

17 Sobre el Canon pali, véase el apartado 4.1.

18 Acerca de las diferentes escuelas del budismo y su evolución, véase el apartado 4.1.

19 El yogācāra es otra escuela budismo, al respecto véase el apartado 4.1.

20 Loy, op. cit., p. 45.

21 La palabra tantra significa "tejido» en sánscrito y se halla en los himnos védicos del Rigveda. Se entiende como tantra o tantrismo la tradición esotérica del hinduismo y el budismo, entre otras, que se desarrolló aproximadamente a mediados del primer milenio a. C., aunque otros afirman que su existencia es anterior; hoy en día constituye una corriente del hinduismo y del budismo tibetano. Está basado en un conjunto de textos denominados Tantra, atribuidos al mismo Buda, aunque también se atribuyen a seguidores posteriores. Hoy en día, una 
una unidad absoluta denominada yuganaddha, caracterizada por la ausencia de dualidad entre el perceptor y lo perceptible.

También en el budismo tibetano hallamos fragmentos donde se explicita la no-dualidad entre el sujeto y el objeto. La mente conceptualizadora es la que crea la ilusión del objeto. En el Yoga del Conocimiento de la Mente, que se atribuye a Padmasambhava, se hace mención de ella como sigue: «Al no existir verdaderamente la no-dualidad, el pluralismo es falso. Hasta que no se transciende la dualidad y se realiza el estado de un solo sabor, es imposible alcanzar la iluminación. [...] El ignorante sólo ve la dualidad externamente transitoria» ${ }^{22}$.

En el budismo zen (véase el apartado 4.4.) también se halla la misma acepción de no-dualidad. Experimentar el satori-lo que equivale a la iluminación-, es un modo de realización de la no-dualidad: se trata, por lo tanto, de recorrer el camino sapiencial a través de la experiencia y no de una percepción mental especulativa que puede ser aprehendida mediante el intelecto y la razón. El mismo Suzuki afirma en sus Ensayos sobre budismo zen que no existe separación alguna entre el conocedor y lo conocido.

En el caso del taoísmo, no encontramos fragmentos tan explícitos sobre la no-dualidad entre el sujeto y el objeto en ninguno de sus textos clásicos más significativos, aunque se sugiere, siempre de modo velado y enigmático, que la experiencia del Tao es no-dual.

\section{La no-dualidad en el taoísmo}

\subsection{La doctrina del Tao (Dao)}

En el siglo XX el taoísmo penetró en Occidente con fuerza procedente de China. Tao (dào en pinyin) tiene varios significados: «camino», «senda»; «vía»o «camino» entendido como «método»; «doctrina» o «enseñanza». Se desarrolló a

de sus acepciones en Occidente concibe el tantra como un sistema de prácticas yóguicas relacionado con el control de la respiración o pranayama y la energía sexual.

22 Este fragmento atribuido a Padmasambhava procede de: Evans-Wentz, Tibetan Book of Great Liberation, pp. 206 y 232. 
partir de Lao Zi ${ }^{23}$ y el Tao Te Ching ${ }^{24}$, su escrito principal. Entre otras traducciones, en español también se conoce como "Regla del Camino y de la Virtud» ${ }^{25}$. Lao Zi vivió alrededor del 400 a. C., aunque el libro del Tao puede haber estado recopilado por varias personas (cf. Watts, 2005: 15), lo cual dificulta su datación exacta.

Fundamentado en el «taoísmo filosófico» de Zhuang Zi y Lie Zi, el taoísmo, en su origen, es un sistema filosófico que ofrece «una gran sabiduría para vivir, así como consejos para aplicar en los asuntos cotidianos. (...) una forma de comprender el mundo y vivir en él (...)» (Watts, 2005: 33). El taoísmo no es, por lo tanto, una religión ${ }^{26}$.

Algunos conceptos taoístas como el yin y el yang resultan ya familiares en Occidente. Aunque ambos son opuestos y, por lo tanto, duales, ambos son interdependientes y se complementan como una unidad. Del mismo modo, no hay femenino sin masculino, ni noche sin día, y viceversa; el universo ha de mantenerse en este equilibrio inestable. El tao es, sin embargo, una tercera fuerza que comprende ambos opuestos. El primer fragmento del Dao De Jing contiene, sucintamente pero concentrado, toda la esencia de la doctrina del tao: «El dao que puede expresarse con palabras, no es el dao permanente» ${ }^{27}$; «El dao es vacío, pero su eficiencia nunca se agota. Es un abismo, parece el origen de todas las $\operatorname{cosas}^{28}{ }^{28}$. En la doctrina, el tao es «una realidad de la cual emerge el cosmos» ${ }^{29}$;

23 Observamos diversas transliteraciones: Lao zi en pinyin («Viejo Maestro»), también como Lao Tsé o Lao-Tzu.

24 Dào Dé Jìng en pinyin. En el taoísmo, la connotación de tao describe un proceso esencial del universo que implica el fluir y el movimiento; dé significa «virtud», tanto moral como una cualidad personal; jing significa "escritura» o "doctrina». Prescindiremos en su transliteración de los diacríticos sobre las vocales ( ', ', ', ' ) que indican los tonos en pinyin.

25 Tal como lo denomina Román López (2004). Otras traducciones son: «La Escritura del Camino y la Virtud», «El Gran Libro del Camino y su Poder», «La Doctrina de la Senda y sus Virtudes» o simplemente como «El libro del Tao».

26 Según Román López (2004: 384), también hay un «taoísmo religioso», cuyas enseñanzas llegan a ser incluso contradictorias: Lao Zi ocupa el lugar principal en este panteón taoísta, un dios inmortal, junto con una serie de héroes folclóricos, generales famosos y sabios. El taoísmo como religión es posterior y arraigó en Taiwán; tomó elementos del confucianismo, budismo y ciertas religiones populares. Cuando el budismo llegó a China, la escuela budista Ch'an, se vio influenciada por el taoísmo; más tarde entra en Japón y da origen al budismo zen.

27 Lao zi, op. cit., p. 91.

28 Lao zi, op. cit., p. 97.

29 Román López (2004), op. cit., p. 386. 
«una especie de sílaba sin significado que indica el misterio que nunca podremos comprender (la unidad que existe tras los opuestos)» ${ }^{30}$.

\subsection{Elementos no-duales en el taoísmo}

La esencia del tao es no-dual en sí: «existía antes del Cielo y de la Tierra», no es posible decir de dónde proviene, pues no tiene ni principio ni fin. Es madre de la creación y principio de todos los seres, según Lao zi; «El Tao es la gran unidad, la unidad única en la que se trascienden todos los contrarios, la ausencia de dualidad» (Román López, 2004: 387). De este modo, vemos cómo se explica la multiplicidad a partir del uno: «El dao engendra al uno, el uno engendra al dos, el dos engendra al tres, el tres engendra los diez mil seres. Los diez mil seres contienen en su seno el yin y el yang $(\ldots) »^{31}$.

La no-pluralidad del mundo (según Zhuang zi, «No hay nada que no sea esto; no hay nada que no sea eso») ${ }^{32}$ y de los objetos y cosas contenidos en él que forman una totalidad, muestran una naturaleza no-dual, pero esta concepción se diferencia de la visión de carácter monista, pues no se trata de una substancia única indiferenciada; precisamente, el tao es esta totalidad «indivisible y carente de principio y final $»^{33}$; el tao también se califica de «absoluto espiritual» ${ }^{34}$.

No encontramos en los textos clásicos más importantes del taoísmo referencias explícitas claras hacia la no-dualidad como en otras sabidurías orientales. Sin embargo, desde el principio del Dao De Jing encontramos implícita la nodualidad del origen de todo.

La negación en la no-dualidad va más allá de la negación lógica: el «no-ser» que, según se desprende de algunos capítulos del Dao De Jing, es anterior al ser: «El movimiento del dao, es transformación de contrarios [...] Las cosas del mundo nacen del ser $(y o u)$, el ser nace del no-ser $(w u) »^{35}$. La oposición ser/no-ser se

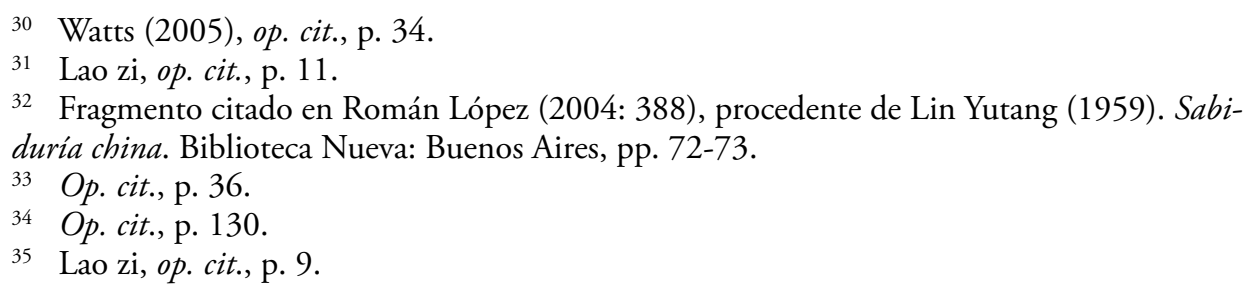


disuelve, de modo que sólo son contrarios para la mente conceptualizadora humana; sólo son dos formas de una única cosa, depende del momento temporal (humano y limitado, pues el continuum temporal, la eternidad, es no-dual y de nuevo es la mente humana la que fragmenta el tiempo), pero en realidad es uno en esencia.

\section{La no-dualidad en el hinduismo}

\subsection{La esencia del hinduismo: ¿̨religión o filosofía?}

Los mismos hinduistas conciben el hinduismo como una filosofía de vida, pero no es ni un sistema filosófico ni una religión, como en el caso de las otras sabidurías orientales. Sin embargo, el hinduismo hoy en día presenta un amplio abanico de innumerables sectas con sus correspondientes cultos, ritos y ceremonias, panteón de deidades, sistemas filosóficos y disciplinas espirituales. En su vertiente religiosa, el hinduismo es el resultado de una tradición sin fundador, ni texto oficial, sin iglesia organizada con jerarquía estricta, ni de carácter dogmático; por otra parte, es el resultado de enfoques diversos y ramas no exentas de contradicciones. En su camino para alcanzar la divinidad diferencian vías como la meditación, el conocimiento, el trabajo y la devoción ${ }^{36}$.

El hinduismo se remonta probablemente a la época prearia, a las creencias y prácticas de una civilización que floreció en el valle del Indo entre el 3000 y el 1500 a. C., hasta las primeras invasiones arias. Los primeros textos del hinduismo son los Veda, himnos que reflejan creencias tanto religiosas y mágicas como filosóficas entre los s. XV y X a. C., aunque predomina en ellos el carácter religioso. Los Veda proceden muy probablemente de una tradición oral, y fueron escritos en sánscrito antiguo.

Los textos religiosos hinduistas se dividen en shruti (lo escuchado) y smriti (lo recordado), o en otros términos, se trata de la revelación frente a la tradición.

Los shruti incluyen los cuatro Veda, los Upanishad y los Vedanta Sutras. Los himnos védicos se agrupan en cuatro colecciones (sambita):

36 Cf. Román (2004), op. cit., p. 236. 
1. Rig Veda, o Veda de las estrofas, los más antiguos de todos, himnos de alabanza a los dioses en verso escrito en antiguo sánscrito védico;

2. Sāma Veda o Veda de las melodías, versos métricos recitados durante las ceremonias que celebraban los brahmanas;

3. Yajur Veda o Veda de las fórmulas, escritos en prosa y recitados durante un sacrificio de fuego;

4. Atharva Veda, colección de himnos originales mezclados con encantamientos poderosos para procurar una larga vida, curar enfermedades, protegerse y vencer a los enemigos, entre otros.

Con el paso del tiempo, surgieron los Brahmana, obras litúrgicas dirigidas a los oficiantes de los rituales; los Aranyaka, obras de carácter secreto y mágico que contienen fórmulas (mantra) y ritos sagrados, y los Upanishad, tratados místicos.

Los smriti (lo recordado) comprenden: los Purana, obras de carácter épico; los Itihasa (poemas épicos como el Mahabharata y el Ramayana), etc. El Mahabharata, recoge la lucha entre los Pandava y los Kaurava; el Ramayana o Gesta de Rama, relata la historia de Rama, e incluye dos extensos tratados filosófico-morales: el monólogo de Bhima poco antes de morir y el Bhagavad Gita o Canción del Señor, que fueron compuestos por generaciones distintas de poetas entre los s. III a. C. y III d. C.

Con un complejo panteón de numerosas divinidades, evoluciona a dos corrientes básicas de culto: 1) el vishnuismo o vaishnavismo, basado en la adoración de Vishnú como divinidad única, que desplazó a Brahma, y se manifiesta a través de sus diez encarnaciones o avatâras, -el noveno avatar es el Buddha; 2) el shivaísmo o shaivismo que rinde culto a la divinidad exclusiva de Shiva (dios destructor) sin avatâras. También se profesa el culto a la diosa Durga o Kali y a otras deidades como Mitra, Indra o Ganesha. Además, el panteón indio presenta toda una serie de seres sobrenaturales, benévolos y maléficos, demoniacos, seres humanos divinizados; seres animados como animales y plantas, e inanimados, como los ríos, abstracciones y poderes personificados ${ }^{37}$.

37 Cf. Román López (2004), op. cit., p. 253. 
Dentro del hinduismo, el vedanta advaita destaca como escuela filosófica no dual por excelencia.

\subsection{Algunos conceptos centrales del hinduismo}

En la doctrina hinduista encontramos conceptos hoy en día conocidos en Occidente como reencarnación o karma, pero otros probablemente menos habituales en el acervo popular como dharma o samsara. Sin embargo, debido a la popularización de algunos de estos términos a través de la literatura y el cine, o del hatha yoga, hemos creído conveniente dar una definición básica para evitar interpretaciones idiosincráticas.

La creencia en la reencarnación no es exclusiva del hinduismo, sino común a muchas de las sabidurías orientales, o de otras creencias y religiones más cercanas a Occidente, bajo otro nombre y con mayor o menor grado de diferencia en matices, como la metempsicosis y la transmigración de las almas ${ }^{38}$.

El término karma significa básicamente «acción», aunque se ha convertido en una doctrina fundamental compartida por el hinduismo y el budismo, con sutiles diferencias de matices. Explicado de modo un tanto simplista, el karma determinará la forma en que el alma (ätman) se reencarna, como consecuencia del resultado de las acciones llevadas a cabo. El ciclo de nacimiento, muerte y reencarnación, denominado samsära, seguirá mientras que el hombre esté atado a la vida debido a su ignorancia, el apego y sus deseos. La meta última del hinduista es escapar del ciclo del samsāra y fundir su alma con Brahman, lo Absoluto (lo que los taoístas denominan Tao). Por otra parte, el significado de dharma es complejo y múltiple: destacamos el significado de «ley» u «orden natural» en el hinduismo ${ }^{39}$, además de "enseñanza o doctrina del Buddha», pero

38 Hay una gran variedad de denominaciones y matices en los diferentes sistemas que contemplan el fenómeno de la reencarnación, cuya exposición sobrepasaría los límites temáticos y espaciales del presente artículo. Cabe destacar aquí su relevancia como concepto fundamental sobre el que se basa las diferentes escuelas hinduistas y budistas, y también en el taoísmo.

39 El término sánscrito dharma tiene múltiples significados: «ley(es) y estructura del universo» (Román/Vélez, 1998: 415). En el budismo, sin embargo, se entiende el dharma como la enseñanza del Buddha (Román/Vélez, 1998: 416; 422), y da origen a la teoría de los dharmas -obsérvese su uso en plural (cf. Román/Vélez, 1998). Sobre el significado de dharma «en el sentido de objetos últimos del análisis irreductibles analíticamente a otras realidades» (Román/Vélez, 1998: 418), los autores diferencian su concepción en el budismo 
se halla también como "característica» o «naturaleza» de algo; también se refiere dharma a los comportamientos y estados mentales morales. Otro significado más general es como «cosa, «realidad», «ente», «algo»; y, por último, también se considera un «estado mental», en su sentido psicológico y epistemológico (cf. Román/Vélez, 1998: 422-423). La variante del hinduismo más relevante por su doctrina no-dual es el vedānta advaita.

\subsection{Vedanta advaita como doctrina no-dual}

Vedānta, palabra sánscrita compuesta por veda (conocimiento) y anta (fin), significa en su conjunto "fin del conocimiento»; también se traduce por «esencia de los Vedas». Por otra parte, advaita significa literalmente «no-dual».

El vedanta pretende llegar al conocimiento verdadero (jñana) que lleva a la liberación $(m o k s a)$. Se dividen en la escuela monoteísta, que eleva a Brahman a la categoría de un dios personal, con atributos, y, por otra parte, la no-dualista, que concibe a Brahman como Nirguna-Brahman, lo Absoluto, sin atributos ${ }^{40}$.

La sabiduría del vedanta advaita está contenida principalmente en las Upanishad, el texto más especulativo y filosófico de los textos védicos, y en los Brahma Sütras y el Bhagavad Gìtā. Badarayana se encargó de sistematizar la doctrina del vedanta que quedó recogida en el Vedānta Sutra (200 a. C.). El vedanta advaita fue expuesto por Śankara (ca. 788-820) en el Vākyavritti. ¿En qué consiste la nodualidad del vedanta advaita a diferencia de los sistemas monistas?:

Śamkara's system is best labeled "non-dualistic" rather than "monistic" to distinguish it from any position that views reality as a single order of objective being. Advaita Vedānta is concerned to show the ultimate non-reality of

pre-escolástico, escolástico y abhidhármico; mientras que en el budismo abhidhármico se
entiende dharma como aparece en la última cita, para el budismo pre-escolástico «ni los
dharmas son manifestaciones de una y la misma realidad absoluta, ni los dharmas son una
multiplicidad de pequeñas realidades absolutas (separadas y constitutivamente no relativas)»
(Román/Vélez, 1998: 420). Podemos observar que se distancia del monismo y del pluralismo,
puesto que el "Buddha afirma que las cosas no son una y la misma realidad (...) ni tampoco
muchas realidades últimas e irreductibles.» (Román/Vélez, 1998: 420). 40 Cf. Martín (1998: 31). 
all distinctions -that Reality is not constituted by parts, that in essence it is not-different from the Self. The unity or "oneness" that Advaita upholds, as we will see later in close detail, does not require variety or multiplicity, as is the case with most monistic views, in order to be affirmed.

( $\mathrm{El}$ sistema formulado por Śankkara se puede calificar mejor con la etiqueta de «no-dual» que de "monista», para diferenciarlo de cualquier posición que considere la realidad como un orden simple de existencia objetiva. El vedanta advaita se preocupa de mostrar la no-realidad máxima de cualquier distinción, que la Realidad no está constituida por partes y que en esencia está no-diferenciado del Sí mismo. La unidad o "unicidad» que propugna el advaita, como veremos más tarde con todo detalle, no requiere variedad o multiplicidad, como es el caso de la mayoría de las perspectivas monistas, para que se pueda afirmar su existencia.») ${ }^{41}$

De su doctrina se deriva una guía práctica de experiencia espiritual individual, que consiste en un camino de autorrealización en el que se llega a conocer la verdadera naturaleza de la realidad, que es Brahman, lo Absoluto: he aquí donde reside "el fin del conocimiento». Para llegar al conocimiento verdadero, el sujeto ha de superar el engaño de su existencia como ser separado y discreto del resto del universo, del límite del yo impuesto por la mente y sus percepciones, darse cuenta de que no existe diferencia entre sujeto y objeto -lo cual nos remite de nuevo a la tercera acepción de no-dualidad de Loy-, con lo que se llega a trascender el mundo porque es una ilusión $(m \bar{a} y \bar{a})$; sólo Brahman es real. La filosofía de liberación que propone consiste en que el sujeto, el individuo (ātman) llegue mediante la experiencia a la unión con Brahman.

Según Śankkara, el universo es Brahman en su totalidad, que no tiene ni principio ni fin, sin embargo, él no niega la existencia del mundo fenoménico categóricamente. La materia inconsciente no puede originar un mundo donde hay seres conscientes. La causa eficiente e inteligente debe ser inmanente al mundo: el Absoluto es consciente y está en todo. Siempre que exista una experiencia de diferenciación, un "yo», un "sujeto» y un «objeto», está presente māya ; siempre que no percibimos la realidad como uno, es una manifestación de $m \bar{a} y \bar{a}$. De este modo se manifiesta el mundo en una pluralidad, pero esta pluralidad es producto

41 Deutsch (1973: 3). La traducción ha sido realizada por el autor del presente trabajo. 
de la ignorancia (avidyā) del «yo» sobre su origen y de su percepción subjetiva que le lleva a aprehender los objetos del mundo como entidades discretas y separadas del perceptor. Cuando el sujeto vuelve a percibir el mundo sin separación entre sujeto y objeto, llega al saber verdadero (jñana), lo que implica a su vez la liberación (mokșa).

El camino de liberación que propone el vedanta advaita consiste en interiorizar la no-dualidad del mundo. De este modo, el vedanta advaita destaca como sistema no-dual por antonomasia.

Los hindúes diferencian entre la percepción savikalpa (con superposición conceptual) y nirvikalpa (sin superposición conceptual). La percepción savikalpa surge cuando ańadimos preceptos mentales y asociamos con el lenguaje la percepción nirvikalpa, que es una "percepción pura» que «se halla disociada del nombre» (Loy, 2000: 58), según el sistema pluralista. La propuesta de las tradiciones no-duales es llegar a la percepción nirvikalpa "pura», ya que la percepción habitual es savikalpa y no sólo entendida esta última como una superposición, sino al representar y aprehender la realidad con el lenguaje, aquello que se nos representa como realidad es una mera categorización lingüística.

Por otra parte, Śankkara afirma que nuestra percepción del universo es la continua percepción de Brahman, aunque la ignorancia nos impida reconocerlo, así que la conciencia básica no-dual del ser humano se ve limitada por la mente y las formas objetivas, o en el caso de que no se halle limitada, hay que apartar el velo de la ignorancia para volver al conocimiento puro, a Brahman.

De este modo, el ser humano es capaz de llegar a la experiencia no-dual. Por otra parte, nuestra experiencia empírica habitual se sitúa en el plano dual de la verdad relativa, pero la experiencia trascendental es de nivel no-dual. La eliminación del velo de la ignorancia lleva a la comprensión de la identidad entre Brahman y el yo. Aunque existiera el yo, este no puede percibirse a sí mismo, igual que el ojo no se puede ver a sí mismo ni un cuchillo puede cortarse a sí mismo. Toda imagen que puede uno obtener de sí mismo es el reflejo a través de un espejo. En el caso de que solo existiera el yo, ese yo no puede ser conocido, puesto que si se conoce se convierte en un objeto ${ }^{42}$. Śankara incide en este punto: mediante la objetivación de la conciencia, la identificamos con el pensamiento, el cuerpo con sus atributos y posesiones..., y ésta es la ignorancia básica de la

42 Cf. Loy, op. cit., p. 155. 
que debemos librarnos para alcanzar la liberación. Vivir en la consciencia de la no-dualidad del ser y el universo supone un paso más hacia esta consecución.

\section{La no-dualidad en el budismo}

\subsection{Buddha y las escuelas budistas}

Frente al cristianismo, judaísmo o islamismo, el budismo no es una religión revelada y carece de una palabra divina revelada; su trasmisión fue oral en origen. Actualmente, el budismo ha derivado en una amplia variedad de escuelas.

Buddha (en sánscrito "el que ha despertado»), se erige en el elemento unificador de todas las variedades. Vivió entre el 556 y el 476 a. C. en las repúblicas al norte del Ganges ${ }^{43}$; no tiene carácter divino, ni es un mesías o profeta, sino un ser humano que ha alcanzado la iluminación, y como tal ha logrado trascender su condición humana.

El pensamiento budista de la India se suele dividir en tres grandes fases ${ }^{44}$ :

1) Budismo antiguo o pre-escolástico, desde la época del Buddha (ca. 560480 a. C.) hasta la escisión del budismo en escuelas (ca. 350 a. C.);

2) Budismo escolástico o abhidhármico, desde ca. 350 a. C., hasta el siglo I a. C., aunque no desaparece, sino que coexiste con el budismo posterior, por una parte, y se integra con el budismo Mahāyāna ${ }^{45}$, por otra. En este período se diversifica en numerosas escuelas (unas treinta), con sus propios textos sistemáticos (Abhidharma) e interpretaciones de la Enseñanza (Dharma). La escuela Theravāda ("doctrina de los ancianos») es la única que sigue existiendo en Sri Lanka, Tailandia y Birmania.

3) Budismo Mahāyāna, desde el s. I a. C. hasta la desaparición del budismo indio en la Edad Media. Se escriben nuevos sermones (sütras) que se atribuyen

43 Cf. Román López (1994: 85-103).

44 Cf. Román/Vélez, op. cit., pp. 411-412.

45 Escrito aquí Mahāyāna, en mayúscula y con la transliteración de la ā, en analogía a las fuentes citadas o de referencia; en el resto del trabajo, se adopta la forma adaptada al alfabeto latino mahayana, sin signos fonéticos diacríticos. 
al Buddha histórico. Las dos escuelas filosóficas principales son la Mādhyamaka y la Yogäcära. A partir de aquí el budismo se extiende por el Extremo Oriente en Tibet, China, Corea, Japón, etc.

La vida y pensamiento del Buddha se recogen en dos tradiciones: a) el Canon septentrional, en sánscrito, originario del noroeste de la India; b) el Canon meridional, en pali, usado al sur de la India, más fiel al pensamiento del Buddha y al de sus inmediatos discípulos, reflejado en los Sermones medios de Buddha. Tras su muerte, sus adeptos celebraron varios concilios con la finalidad de hacer frente a las divergencias de su enseñanza. En el s. I d. C. se dividió en Hìnayāna y Mahāyāna. La escuela Theravāda constituye el denominado Pequeño vehículo (Hìnayāna) y es conocida también como Escuela del Sur porque predomina en Asia sudoriental. Tiene como referencia el Canon pali, fijado en Sri Lanka alrededor del 69 al 40 a. C., con una rica literatura. Hoy en día la vertiente laica del budismo que propugna la práctica de la meditación como vía para alcanzar el nirvana ${ }^{46}$ ha cobrado una enorme fuerza ${ }^{47}$.

Mientras que el Hīnayāna mantuvo su unidad, el Mahāyāna o Gran Vehículo, conocido también como Escuela del Norte, se escindió en numerosas sectas; lamaísmo en el Tíbet, Nepal y Mongolia; el budismo tibetano está basado en el tantrismo del norte de India, denominado también Vayrayāna («Vehículo de diamante»). En la actualidad perdura una multitud de escuelas budistas con sus prácticas, rituales y doctrinas propios.

\subsection{La doctrina budista y sus conceptos básicos}

El budismo presenta en su doctrina muchos puntos en común con el hinduismo, por ejemplo, la doctrina del karma o la de la reencarnación. La filosofía budista pretende liberar al ser humano del sufrimiento para alcanzar el nirvana, y su doctrina de los dharmas, de carácter soteriológico, es común a todas sus escuelas.

46 Para evitar la trivialización del término, se entiende el nirvana como el «Estado de iluminación perfecta alcanzado por los budas y arhatas; quienes han obtenido este estado dejan de acumular consecuencias kármicas y no renacen más en el samsara cuando mueren» (Trainor, 2006: 239).

47 Cf. Trainor, op. cit., pp. 120-121. 
Nāgārjuna fundó la escuela Mādhyamaka en el s. II d. C. Mientras para Buddha el mundo carece de existencia substancial, para Nāgārjuna está vacío de existencia inherente o propia y, por lo tanto, los dharmas ${ }^{48}$ tampoco tienen una existencia inherente, lo cual implica que su origen y cese es también interdependiente y esto equivale a afirmar que carecen de existencia substancial. La vacuidad representa un concepto fundamental del budismo.

El hinduismo y el budismo comparten la doctrina del samsāra, el ciclo incesante de nacimiento, muerte y renacimiento, pero el budismo niega la existencia de un alma inalterable que pueda transmigrar de una encarnación a la siguiente (anätman), mientras el hinduismo postula la existencia del ätman, un alma inalterable. El budismo considera que los seres humanos, como todo lo demás fenómenos, están sujetos a un cambio constante, no tienen permanencia, por lo cual no puede haber una entidad fija que constituya el alma; de ahí la impermanencia como enseñanza fundamental budista.

Las Cuatro Verdades Nobles -aceptadas por todas las escuelas budistas-, se consideran la primera enseñanza de Siddharta Gautama y muestran el camino hacia el nirvana, y son: 1) el sufrimiento (dukkha);2) su origen; 3) su cese; 4) la vía para su extinción: el Óctuple Sendero. La doctrina de la liberación budista del dharma gira en torno al sufrimiento: el sufrimiento es el daño; el deseo es la causa de la enfermedad; al erradicar el deseo se cura el daño y se produce la sanación. De este modo, se llegará a comprender las leyes y la estructura del universo, es decir, el dharma, que le conducirá al despertar o iluminación, para alcanzar el nirvana como liberación del sufrimiento, mediante el desapego, el amor incondicionado y la recta visión del mundo ${ }^{49}$. Se persigue la comprensión de la realidad como método de liberación, de la impermanencia (anicca) y de la insubstancialidad (anattā, «no yo»). Su no comprensión se convierte en fuente del sufrimiento, cuya causa reside en el deseo y el consiguiente apego. La Cuarta Verdad Noble describe la senda que lleva a la extinción del sufrimiento, el denominado Sendero Medio, llamado también Noble Sendero Óctuple. El cese

48 Se entiende aquí por dharmas como objetos discretos irreductibles sobre los que se sustenta la realidad (véase en el apartado 3.2. las diferentes acepciones de dharma, tanto en el texto principal como en la nota a pie de página).

49 Cf. Román/Vélez, op. cit., p. 415. 
del sufrimiento llega a aquél que consigue alcanzar la iluminación, al cesar todo deseo y lograr la liberación mediante las propias acciones.

\subsection{Elementos no-duales en el budismo}

El budismo contiene en su doctrina elementos no-duales en diversas medidas según la escuela, aunque no siempre se expresa explícitamente. El budismo mahayana, «abunda en referencias mucho más explícitas a la percepción no dual» (Loy, 2000: 57).

Como hemos expuesto anteriormente, el principal motivo de sufrimiento según el Buda es el apego, no sólo a los deseos, sino también hacia las experiencias sensoriales y los eventos puramente mentales. El apego es básicamente de naturaleza epistemológica, ya que distorsiona la percepción de las cosas mediante los sentidos, y sólo a través de ellos podemos percibir las «apariencias» de los objetos. Pero el lenguaje es un sistema de «re-presentación» que permite referirnos a algo que no está presente y permite actualizar el «apego a distancia», acentuando así su naturaleza dual.

El mundo no está compuesto por un conjunto de objetos discretos y bien diferenciados, sino que es nuestro sistema de representación, el lenguaje, lo que divide el mundo y determina así nuestra percepción de él. A diferencia del hinduismo, el budismo (a excepción del yogacara, apunta Loy) no afirma la pluralidad del mundo, sino que sostiene que todo se haya vacío (śünya).

Y esta formulación resulta bastante razonable, puesto que el pensamiento dualista, en la acepción más amplia del término, incluye todo proceso de etiquetado conceptual, de ahí que no podamos aseverar siquiera la existencia de una totalidad no-dual. Después de todo, el Tao que puede ser nombrado no es el verdadero Tao. ${ }^{50}$

50 Loy, op. cit., p. 39. 
Esta vacuidad (śuñyata), que postula el budismo mahayana, incluye al Ser, el Brahman del vedanta: aquí reside una diferencia básica entre ambas doctrinas. La experiencia no-dual de nuestra percepción habitual que propone el mahayana no se relaciona con una existencia independiente de los objetos, de modo que

(...) acabamos confundiendo la permanencia del evento (la autoluminosidad de Brahman, por ejemplo) con un objeto físico (la materia independiente) ¿Qué es, pues - desde una perspectiva no-dual- lo que vemos? No tanto, por cierto, un objeto material independiente -que permanece pasivo e inalterado- sino śūnya, una conciencia activa que resplandece por sí sola. ${ }^{51}$

\subsection{La no-dualidad en el budismo Zen}

El budismo Zen se conoce en Occidente como la variedad budista propia de Japón, donde ha calado profundamente desde el s. XII. Hunde sus raíces en el budismo hindú, y llega a Japón a través de China, donde surge el budismo Ch’an. $\mathrm{Al}$ igual que otras sabidurías orientales, el budismo Zen «no es una religión ni una filosofía; no es una psicología o cierto tipo de ciencia», sino "un camino y concepción de vida que no pertenece a ninguna de las categorías formales del pensamiento occidental moderno" (Watts, 2006: 23). Se caracteriza por «la práctica de la meditación y por un estilo de adoctrinar irreverente» ${ }^{52}$, y también por su especialización en distintas técnicas de meditación como el koan (preguntas o historias que plantean los maestros a los alumnos zen) o el za-zen (meditación sentada).

Cuatro principios caracterizan el $\mathrm{Zen}^{53}$ : 1) la transmisión fuera de las enseńanzas ortodoxas budistas por medio de sus linajes; 2) la creencia de que la verdad no depende de doctrinas establecidas, y en el valor de la experiencia por encima del de las escrituras; 3) apuntar directamente a la mente, y el énfasis en examinar la propia naturaleza original; 4) la consecución de la iluminación (kenshō).

51 Loy, op. cit., p. 95.

52 Blum (2006). «Chan y Zen: El camino de la meditación». Trainor, op. cit., pp. 150 y ss.

53 Ibid., p. 50. 
La autoridad en el Zen no proviene de textos sagrados escritos, sino de las enseñanzas de linajes de maestros iluminados -principios 1) y 2)-, por lo que el Zen se conoce como el «budismo de la iluminación»: lo único que puede llevar a alcanzar la iluminación total (satori) es la experimentación de una mente totalmente despierta, el kenshō-principio 4)-, que es el camino de la autorrealización previo al satori, equivalente al nirvana. El principio 3) apunta hacia la meditación, de tal modo que el Zen cree que la verdad profunda se puede transmitir de mente a mente y que las palabras son incapaces de hacerlo.

Entre las diferentes escuelas de Zen, se estableció en China el Ch'an, en Vietnam el Zen (Thien); en Corea, el Zen (Son) dio origen a la escuela Chogye. En Japón se distinguen dos escuelas desde el s. XII: la Rinzai (Linji) y la Soto (Caodong). La tercera, conocida como Obaku, entró en el s. XVII también procedente de China.

Según Suzuki, la experiencia del satori es una realización de la no-dualidad; en su obra Ensayos sobre budismo zen, afirma que no existe separación alguna entre el conocedor y lo conocido.

Una clave fundamental a la hora de destacar los aspectos no-duales del budismo zen lo constituye el concepto de «mente única» de Huang Po, maestro chino de la escuela Ch'an: «Todos los Budas y todos los seres vivientes son la Mente Única; no hay otro Dharma que éste. Esta Mente que carece de principio, no surge a la existencia y no cesa a la existencia ${ }^{54}$. Así, todo lo viviente y los budas constituyen esta Mente Única, que es una sola esencial espiritual. Sin embargo, en otro momento, Huang Po niega la realidad de los objetos que se perciben mediante los órganos sensoriales, les niega incluso la existencia objetiva. De este modo, los objetos percibidos deben ser uno con la mente que percibe, debe ser una misma cosa: éste es el momento en el que se alcanza la iluminación: «Se sostiene que existe algo que hay que comprender o alcanzar aparte de la mente y, por tanto, se usa a la mente para buscarlo. (Eso implica) no entender que la mente y el objeto de su búsqueda son uno" $"$.

En la literatura ch'an se halla una formulación prototípica, «como si ahora estuviese sordo y ciego», que además de describir a aquel ser humano que adolece

54 Cita según http://www.tradicionperenne.com/budismo/CHAN/LINCHI/HUANGPO/ MenteUnica.htm. Última consulta: 24 de agosto de 2010.

55 Huang Po, Chu Ch'an, citado en Watts (2006), op. cit., p. 166. 
de una verdadera percepción espiritual, tiene otro significado opuesto, y se refiere con ella a aquél que ha trascendido toda dualidad con su percepción. También el sentido del oído puede brindar una experiencia no-dual: escuchar la música con los ojos cerrados permite en ocasiones, -a veces con ayuda de sustancias psicotrópicas para alcanzar un estado de conciencia o percepción alterada, recogido a menudo en la literatura ${ }^{56}$, lleva a diluirse al melómano, o músico, de modo que fluye con la melodía, las notas, se funde con el sonido, se hace uno con la música; es un satori en el que sólo parece existir el sonido de la música en un aquí y ahora eternos: esto es una experiencia inmediata y directa de no-dualidad. Monjes y discípulos dedicados al Zen dan cuenta de experiencias no-duales similares con el sonido de la campana: al alcanzar el estado en el que uno no distingue entre el yo, la campana, el sonido que produce, el universo, se produce el kenshō, la iluminación o autorrealización, que es otra manera de alcanzar una experiencia no-dual.

En el Zen, la falta de intencionalidad en el arte se aplica también al deseo de autorrealización, de alcanzar el kenshō; de ahí los métodos sorprendentes de los maestros Zen hacia los discípulos, como los desconcertantes koans, ya que el despertar espontáneo, o la iluminación súbita es posible sin el deseo de alcanzarla. Cuando media el deseo de llegar a ser iluminado, el mismo deseo revela la falta de iluminación, lo que nos sumerge en un estado dual, cuando la naturaleza del ser humano es no-dual.

\section{Recapitulación y conclusiones}

Con el propósito de seguir su rastro en los textos y las bases doctrinales de diversas corrientes religiosas y sistemas filosóficos, subsumidos bajo el concepto de sabidurias orientales, se ha tomado como punto de partida las diferentes acepciones del término no-dualidad según Loy (2000). La no-dualidad es una propuesta para superar la conceptualización y percepción dualista del mundo en las que vive el ser humano. Para ello, el individuo ha de recorrer su propio camino experiencial, para llegar a la «no-dualidad como estado último de la conciencia», como afirma Consuelo Martín. ${ }^{57}$

\footnotetext{
56 Loy pone un ejemplo de T.S. Eliot precisamente con la música (cf. Loy, op. cit., p. 87).

57 Vedanta-Advaita: Sankara. (Entrevista con Consuelo Martín). UNED Documentos (Fecha de publicación: 7-11-2013). Guion a cargo de María Teresa Román López. [Emitido el 17-02-2001].
} 
El término no-dualidad ha comenzado a popularizarse en Occidente, al igual que otros conceptos, por lo que parece interesante volver a las fuentes de su significado en las sabidurías orientales. Sin embargo, la no-dualidad nos ayuda a cuestionarnos nuestros pensamientos y percepciones del mundo para llegar a su esencia última, tras superar la jaula conceptual del lenguaje, ya que a menudo confundimos el mapa conceptual con la realidad misma que representa.

El camino de liberación propuesto por las sabidurías orientales tratadas en el presente trabajo conduce a la superación de la separación del individuo con el resto del mundo, o formulado como una de las definiciones de no-dualidad, la ausencia de diferenciación entre sujeto y objeto, ya bien sea para alcanzar la unidad con el tao o Brahman, según el taoísmo y el hinduismo, respectivamente, o alcanzar el nirvana o el satori.

La no-dualidad nos muestra paradojas, por una parte, como lo absurdo de la percepción dual que nos lleva a colegir que el universo se compone de objetos discretos e independientes, lo absurdo de buscar los límites del universo con la mente racional, la limitación física de la materia, cuya esencia última está compuesta por los mismos átomos y partículas subatómicas interactuando entre sí, afirma la física cuántica en su búsqueda de los pilares básicos de la materia.

Por otra parte, la no-dualidad cuestiona también los propios pensamientos y acciones, y la relación de ambos con la realidad desde un ángulo ontológico y epistemológico, y remite de este modo a la naturaleza básica del ser y la existencia. En nuestro breve y rápido recorrido, se ha podido observar que la no-dualidad está en la base de las sabidurías orientales más extendidas, ya sea explícita o implícitamente. En ellas hallamos una propuesta de evolución en la senda sapiencial de la propia experiencia más allá de la razón y el intelecto, predominantes en Occidente, para que la verdad última del universo se revele con todo su esplendor.

La permeabilidad cultural y la globalización han permitido la entrada de prácticas importadas de Oriente como la meditación y el yoga, cada vez más extendidas en Occidente, o adaptadas en una técnica ecléctica como el mindfulness, todas ellas con el fin de calmar la actividad conceptual mental y sus proyecciones y diluir las apariencias del mundo exterior - proyecciones de nuestra mente o percepciones de nuestros sentidos-, para conectar con nuestra verdadera esencia: solo de este modo se manifestará nuestra naturaleza verdadera y auténtica, para volver a la unidad, solo así volveremos a ser conscientes de la totalidad 
del universo y de que formamos parte de ese todo uno. Esta es la esencia de la no-dualidad.

\section{Bibliografía}

\section{Textos básicos:}

Bhagavad Gita. Con los comentarios advaita de Sankara (1997). Ed. Martín, C. Madrid: Trotta.

El libro de los muertos tibetano (2003). Ed. Prats, R. N. Barcelona: Círculo de Lectores. LAo Zi. El libro del Tao (1978). Madrid: Alfaguara.

Lie Zi. El libro de la perfecta vacuidad (2003). Ed. Preciado, I. Barcelona: Círculo de Lectores.

Los sermones medios del Buddha (2003). Barcelona: Círculo de Lectores.

Luz sobre los Yoga Sütras de Patañjali (2004). Ed. Iyengar, B.K.S. Barcelona: Círculo de Lectores.

NĀGĀRJuna. Mūlamadhyamikakārikā: The Philosophy of the Middle Way (1986). Albany: State University of New York Press. [Edición en sánscrito y traducción inglesa de D. J. Kalupahana].

Upanisad (2003). Ed. De Palma, D. Barcelona: Círculo de Lectores.

Upanisad. Con los comentarios advaita de Sankara (2001). Ed. Martín, C. Madrid: Trotta.

\section{Bibliografía secundaria}

Buum, M. L. (2006). «Chan y Zen: El camino de la meditación». Budismo, en Trainor, K. (sic.) 150-161.

Cavallé, M. (2008). La sabiduría de la no-dualidad. Barcelona: Kairós.

Conze, E. (1962). Buddhist Thought in India. London: George Alien \& Unwin Ltd.

Deutsch, E. (1973). Advaita Vedänta. A Philosophical Reconstruction. Honolulu: University of Hawai Press.

Deutsch, E./ Dalvi, R. (eds.) (2004). The Essential Vedānta: a New Source Book of Advaita Vedānta. Bloomington: World Wisdom. 
Katz, J. (ed.) (2007). One. Essential Writings on Nonduality. Boulder: Sentient Publications.

LEWIS, T. T. (2006). «La condición humana», en Trainor, K. (sic!), 58-63.

Lledó, E. (1974). Filosofía y lenguaje. Barcelona: Ariel.

Loy, D. (1999). Nonduality. A study in Comparative Philosophy. New York: Humanity Books. [1 ${ }^{\text {st }}$ ed.: (1988). New Haven: Yale University Press].

— (2000). No-dualidad. Barcelona: Kairós.

Maharsi, R. (20055). Enseñanzas espirituales. Barcelona: Kairós.

MaIllard, C. (1995). La sabiduría como estética. China: confucianismo, taoísmo y budismo. Torrejón de Ardoz: Akal.

Martín, C. (1998). Conciencia y realidad: estudio sobre la metafísica advaita con la Mandukya Upanisad, las Karika de Gaudapada y comentarios de Sankara. Madrid: Trotta.

- (2002). La Revolución del silencio. El pasaje a la no-dualidad. Madrid: Gaia.

- (2005). Śankara. La visión advaita de la realidad. Madrid: Dilema.

Román López, M. T. (1994). «Buddha: un personaje para la historia del antiguo oriente». Espacio, Tiempo, Forma, Serie II, Ha Antigua, t. 7, 85-103.

- (1996). "Sexualidad mágica y sagrada en la India Antigua: El tantrismo». Espacio, Tiempo, Forma, Serie II, Ha Antigua, t. 7, 65-93.

- (1999a). «Magia y religión en la India Antigua». HISTORIA 16, Año XXIII no 279, 40-48.

- (1999b). «Un acercamiento a Oriente: el budismo». La ciudad de Dios, Vol. CCXII, 2, Real Monasterio de El Escorial, 479-488.

- (2000). «Hacia un encuentro Oriente-Occidente». Éndoxa, Series Filosóficas, 12, UNED, Madrid, 125-140.

- (2004). Sabidurias orientales de la antigüedad. Madrid: Alianza.

- (2010): «Una aproximación a las sabidurías orientales no duales». Éndoxa, Series Filosóficas, 25, UNED, Madrid, 103-127.

Román, M. T./VÉLEz, A. (1998). "La teoría buddhista de los Dharmas». Éndoxa, Series Filosóficas, 10, UNED, Madrid, 411-432.

Silva, A. (2018). Zen I. Ruta hacia Occidente. Barcelona: Herder.

- (2018). Zen II. ¿Qué decimos cuando decimos experiencia? Barcelona: Herder.

- (2018). Zen III. Zensualidad. Barcelona: Herder.

- (2019). Zen IV. El oficio de vivir. Barcelona: Herder. 
Suzuki, D. T. (1993). Leben aus Zen. Eine Einführung in den Zen-Buddhismus. Bern/ München/Wien: O.W. Barth.

Trainor, K. (2006). Budismo. Barcelona: Blume.

Watts, A. (2005). Tao y Zen. Una introducción para Occidente. Barcelona: RBA.

- (2006). El camino del Zen. Barcelona: RBA.

Recursos audiovisuales:

El pensamiento en la India. El hinduismo. UNED, Vicerrectorado de medios impresos y audiovisuales (2003-04). Guion a cargo de María Teresa Román López.

Vedanta-Advaita: Sankara. (Entrevista con Consuelo Martín). UNED Documentos (Fecha de publicación: 7-11-2013). Guion a cargo de María Teresa Román López. [Emitido el 17-02-2001].

Recibido: 18/02/2019

Aceptado: 27/06/2019

Este trabajo se encuentra bajo una licencia de Creative Commons ReconocimientoNoComercial-SinObraDerivada 4.0 
